\title{
COMPARATIVE STUDIES OF VIBRONIC TRANSITIONS IN ONE- AND TWO-PHOTON SPECTRA OF Gd ${ }^{3+} \mathrm{IN} \mathrm{Cs}_{2} \mathrm{NaGdCl}_{6}$
}

\author{
P.J. Dereń, W. Stręk and J. IIAnuza \\ W.Trzebiatowski Institute of Low Temperatures and Structure Research \\ Polish Academy of Sciences, Okólna 2, P.O. Box 937, 50-950 Wroclaw 2, Poland
}

Vibronic spectra of $\mathrm{Gd}^{3+}$ in $\mathrm{Cs}_{2} \mathrm{NaGdCl}_{6}$ were measured under one- and two-photon excitations. Following the vibrational analysis of the $\mathrm{Cs}_{2} \mathrm{NaGdCl}_{6}$ crystal an assignment of vibronic transitions was proposed. It was found that the vibronic transitions in one- and two-photon spectra are combined with the odd parity modes.

PACS numbers: $78.55 . H x$

\section{Introduction}

In the $\mathrm{Cs}_{2} \mathrm{NaGdCl}_{6}$ elpasolite crystal $\mathrm{Gd}^{3+}$ ions are situated in the center of symmetry. Therefore, the electric dipole $f-f$ transitions of active ions are forbidden in the investigated elpasolite crystal. As a result the vibronically induced clectric-dipole lines accompanied by magnetic dipole transitions dominate the spectra. Thus it offers an opportunity for a precise examination of the mechanisms of vibronic transitions (for review see Ref. [1]).

Investigating two-photon induced vibronic spectra of transition metal ions in octahedral systems, McClure et al. [2] discovered that their structure is completely different in comparison with the respective vibronic transitions observed in one-photon spectra. While in the one-photon spectra they were associated with odd parity modes, in the two-photon spectra they were represented by even parity vibrations.

The vibronic transitions of $\mathrm{Gd}^{3+}$ ions in the $\mathrm{Cs}_{2} \mathrm{NaGdCl}_{6}$ crystal were observed in the one-photon excitation spectra by de Vries et al. [3]. It was found that magnetic dipole transitions were associated with odd parity modes. However, the intensity of the latter was lower than intensity of the zero-phonon transitions. Two-photon absorption spectra of $\mathrm{Gd}^{3+}$ in $\mathrm{Cs}_{2} \mathrm{NaGdCl}_{6}$ were reported by Bouazaoui et al. [4]. Theoretical models of the two-photon vibronic transitions were proposed by Sztucki and Stręk [5], and Sztucki [6].

In the present work we report an analysis of the vibronic transitions observed in two-photon excitation spectrum of $\mathrm{Gd}^{3+}$ in $\mathrm{Cs}_{2} \mathrm{NaGdCl}_{6}$. The vibronic lines 
observed in one-photon emission spectrum are presented as well. Following the Raman and infra-red (IR) spectra of the $\mathrm{Cs}_{2} \mathrm{NaGdCl}_{6}$ crystal, an assignment of the observed lines is proposed. The nature of vibronic transitions accompanying one- and two-photon transitions of the $\mathrm{Gd}^{3+}$ ions in $\mathrm{Cs}_{2} \mathrm{NaGdCl}_{6}$ will be briefly discussed.

\section{Experimental}

The $\mathrm{Cs}_{2} \mathrm{NaGdCl}_{6}$ elpasolite single crystal was grown by the Bridgman-Stockbarger method. The cubic space group $F m 3 m$ with the cell constant a $=1.07919 \mathrm{~nm}$ was confirmed by X-ray powder diffraction. The IR spectrum was recorded on a Brucker spectrometer with $2 \mathrm{~cm}^{-1}$ resolution. The Raman spectrum was obtained on a DFS 24 LOMO monochromator. The crystal was excited by an ILA 120 Carl-Zeiss Yena argon laser. A cooled GaAs detector was used. The luminescence spectrum was recorded on a Jobin-Yvon TIIR 1000 monochromator. As a detector an R955 photomultiplier was used. The sample was excited by an LPX 100 Lambda Pliysik excimer laser and by an IID-300B Lumonics dye laser.

\section{Results}

The received infra-red absorption and Raman spectra are shown in Fig. 1. Table I summarises the energies of the unit cell modes and their assignments. The modes with $A_{1 \mathrm{~g}}, E_{\mathrm{g}}$ and $T_{2 \mathrm{~g}}$ symmetries are Raman active, the odd modes $\left(T_{1 \mathrm{u}}\right)$ are only IR active. The $T_{1 \mathrm{~g}}$ and internal $T_{2 \mathrm{u}}$ modes are inactive in Raman and IR

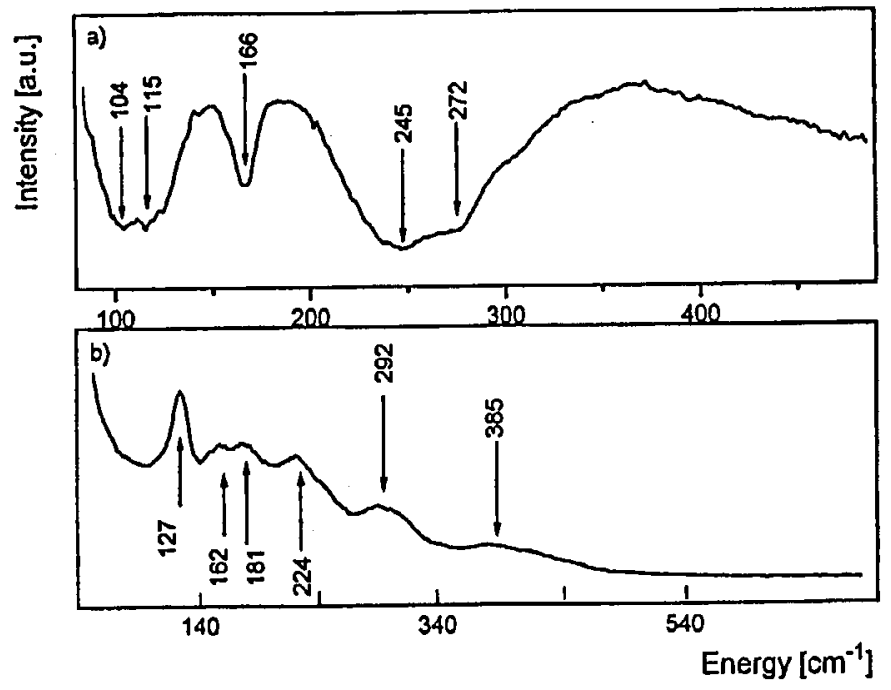

Fig. 1. The $5 \mathrm{~K}$ (a) IR spectrum and (b) Raman spectrum of the $\mathrm{Cs}_{2} \mathrm{NaGdCl}_{6}$ crystal. 
TABLE I

Wave numbers, intensities and vibrational assignment for the elpasolite $\mathrm{Cs}_{2} \mathrm{NaGdCl}_{6}$ single crystal. (s - strong, vs - very strong, $\mathrm{m}$ - middle, $\mathrm{b}-$ broad, $\nu_{\mathrm{s}}$ - symmetric stretching, $\nu_{\mathrm{as}}$ - asymmetric stretching, $\delta_{\mathrm{s}}$ - symmetric bending, $\delta_{\mathrm{as}}-$ asymmetric bending).

\begin{tabular}{c|c|c}
\hline \hline IR & Raman & Assignment \\
\hline & $292,300 \mathrm{~m}$ & $\nu_{1}\left(A_{1 \mathrm{~g}}\right) \nu_{\mathrm{s}}\left(\mathrm{GdCl}_{6}\right)$ stretching \\
$272 \mathrm{vs}, \mathrm{b}$ & & $T^{\prime}\left(T_{1 \mathrm{u}}\right) \mathrm{Na}^{+}$translation \\
$245 \mathrm{vs}, \mathrm{b}$ & & $\nu_{3}\left(T_{1 \mathrm{u}}\right) \nu_{\mathrm{as}}\left(\mathrm{GdCl}_{6}\right)$ stretching \\
& $224 \mathrm{~s}$ & $\nu_{2}(E \mathrm{gg}) \nu\left(\mathrm{GdCl}_{6}\right)$ stretching \\
& $162,181 \mathrm{~s}$ & $T^{\prime}\left(T_{2 \mathrm{~g}}\right) \mathrm{Cs}^{+} / \mathrm{Na}^{+}$translation \\
& & $T^{\prime}\left(T_{1 \mathrm{u}}\right) \mathrm{Cs}^{+}$translation \\
& & $\nu_{5}\left(T_{2 \mathrm{~g}}\right) \delta_{\mathrm{s}}\left(\mathrm{GdCl}_{6}\right)$ bending \\
& $127 \mathrm{vs}$ & $T^{\prime}\left(T_{1 \mathrm{u}}\right)\left(\mathrm{GdCl}_{6}\right)$ translation \\
$115 \mathrm{~s}$ & & $\nu_{4}\left(T_{1 \mathrm{u}}\right) \delta_{\mathrm{as}}\left(\mathrm{GdCl}_{6}\right)$ bending \\
\hline
\end{tabular}

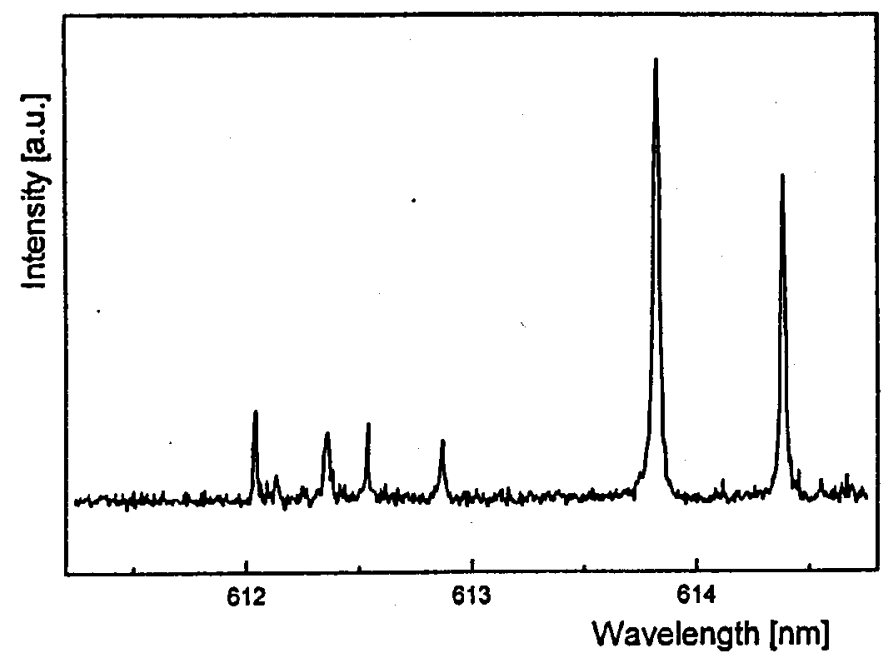

Fig. 2. Two-photon excitation spectrum of the ${ }^{6} P_{7 / 2}$ term at $15 \mathrm{~K}$.

spectroscopy. Among the ten vibrational modes described by Lentz [7] only the $\nu_{3}\left(T_{1 \mathrm{u}}\right), \nu_{4}\left(T_{1 \mathrm{u}}\right)$ and $\nu_{6}\left(T_{2 \mathrm{u}}\right)$ internal modes and the two lattice modes $T^{\prime}\left(T_{1 \mathrm{u}}\right)$ can promote electric dipole transitions. These modes are observed in the IR spectrum (see Fig. 1). The $T_{\mathbf{2}_{\mathrm{u}}}$ vibrational mode, forbidden in the first order approximation may appears in the emission spectrum at about $80 \mathrm{~cm}^{-1}$.

Figure 2 presents two photon excitation spectrum of the ${ }^{6} P_{7 / 2}$ term. On the left site of the zero-phonon lines the vibronic lines are present, their positions are shown in Table II. As far as we are aware the presented spectrum is the 


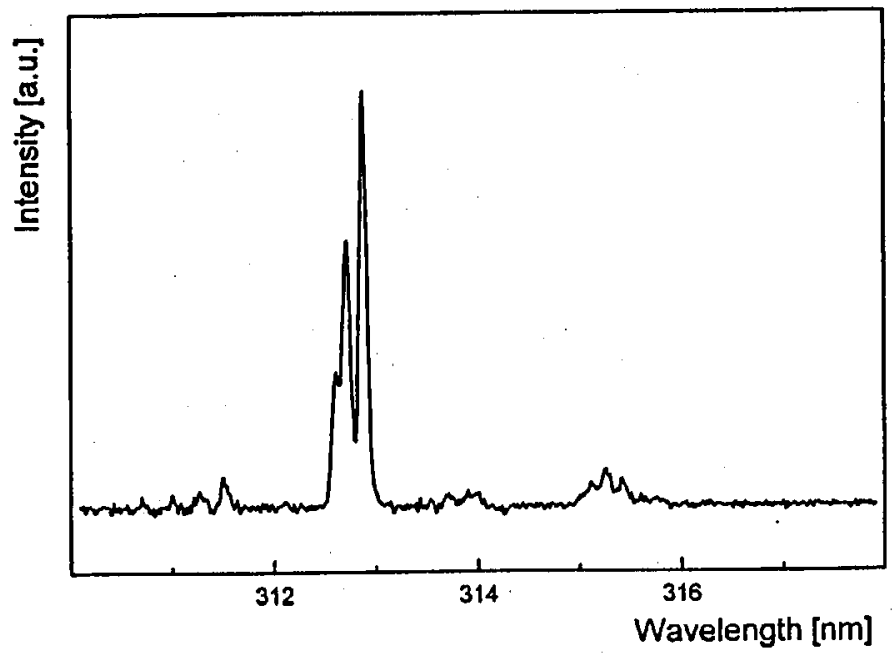

Fig. 3. The $15 \mathrm{~K}$ emission spectrum of the ${ }^{6} P_{7 / 2} \rightarrow{ }^{8} S_{7 / 2}$ transition after one-photon excitation.

\section{TABLE II}

Energies of the lines in the two-photon excitation spectrum.

\begin{tabular}{c|c|c}
\hline \hline Energy & Assignment & Term \\
\hline 32544 & $\Gamma_{7}$ & \\
32574 & $\Gamma_{8}$ & \\
32625 & $\Gamma_{7}+\nu_{6}$ & ${ }^{6} P_{7 / 2}$ \\
32643 & $\Gamma_{7}+\nu_{4}$ & \\
32652 & $\Gamma_{8}+\nu_{6}$ & \\
32670 & $\Gamma_{8}+\nu_{4}$ &
\end{tabular}

second observation of vibronic lines in two-photon spectroscopy after the paper of Meijerink et al. [8]. The zero-phonon lines are associated with the $\nu_{4}\left(T_{1 u}\right)$, and $\nu_{6}\left(T_{2 \mathrm{u}}\right)$ odd vibrational modes of the $\mathrm{GdCl}_{6}^{3-}$ octahedron. The vibronic structure in a one-photon excitation spectrum is much more rich (see Fig. 2. in Ref. [3]).

The position of the $\Gamma_{7}$ component of the ${ }^{6} P_{7 / 2}$ term matches well with the energy of the $308 \mathrm{~nm}$ excimer laser line. The excitation energy relaxes non-radiatively to the ${ }^{6} P_{7 / 2}$ term and a ${ }^{6} P_{7 / 2} \rightarrow{ }^{8} S_{7 / 2}$ radiative transition is observed (see Fig. 3 where emission at $10 \mathrm{~K}$ is presented). In Fig. 3 there are three main peaks, i.e. at $31953 \mathrm{~cm}^{-1}, 31970 \mathrm{~cm}^{-1}$ and $31980 \mathrm{~cm}^{-1}$, they are due to the transitions from the sub-levels of the ${ }^{6} P_{7 / 2}$ term. The distances between $\Gamma_{7}, \Gamma_{8}$ and $\Gamma_{6}$ are the same as in the two-photon spectroscopy spectrum, i.e. $16 \mathrm{~cm}^{-1}$ and $10 \mathrm{~cm}^{-1}$, respectively (see Table II and Table III). On the lower energy site there are two groups of three peaks at about $102 \mathrm{~cm}^{-1}$ and at $258 \mathrm{~cm}^{-1}$ from the center of gravity of 
TABLE III

Energy levels and their assignment observed in the emission spectrum of the $\mathrm{Cs}_{2} \mathrm{NaGdCl}_{6}$ elpasolite single crystal at $10 \mathrm{~K}$.

\begin{tabular}{c|c|c}
\hline \hline Line & $\begin{array}{c}\text { Energy } \\
{\left[\mathrm{cm}^{-1}\right]}\end{array}$ & Assignment \\
\hline 1 & 31696 & $\Gamma_{7} \rightarrow{ }^{8} S_{7 / 2}+\nu_{3}$ \\
2 & 31710 & $\Gamma_{8} \rightarrow{ }^{8} S_{7 / 2}+\nu_{3}$ \\
3 & 31722 & $\Gamma_{6} \rightarrow{ }^{8} S_{7 / 2}+\nu_{3}$ \\
3 & 31852 & $\Gamma_{7} \rightarrow{ }^{8} S_{7 / 2}+\nu_{4}$ \\
4 & 31868 & $\Gamma_{8} \rightarrow{ }^{8} S_{7 / 2}+\nu_{4}$ \\
& & $\Gamma_{7} \rightarrow{ }^{8} S_{7 / 2}+\nu_{6}$ \\
5 & 31879 & $\Gamma_{6} \rightarrow{ }^{8} S_{7 / 2}+\nu_{4}$ \\
6 & 31953 & $\Gamma_{7} \rightarrow{ }^{8} S_{7 / 2}$ \\
7 & 31970 & $\Gamma_{8} \rightarrow{ }^{8} S_{7 / 2}$ \\
8 & 31980 & $\Gamma_{6} \rightarrow{ }^{8} S_{7 / 2}$ \\
9 & 32094 & $\operatorname{Gd}_{1}$ \\
10 & 32116 & $\mathrm{Gd}_{1}$ \\
11 & 32146 & $\mathrm{Gd}_{1}$ \\
12 & 32177 & $\mathrm{Gd}_{1}$ \\
\multicolumn{3}{|c}{ Gd } \\
\multicolumn{3}{l}{ Gd } \\
lographic site (see text for explanation).
\end{tabular}

the ${ }^{6} P_{7 / 2}$ term. One can note that in both groups of small peaks the distances between them are the same as the distances between $\Gamma_{J}$ lines. Therefore these peaks are associated with the strongest vibrational modes $\nu_{4}\left(T_{1 u}\right)$, and $\nu_{3}\left(T_{1 \mathrm{u}}\right)$ of the $\mathrm{GdCl}_{6}^{3-}$ octahedron. The $\nu_{6}\left(T_{2 \mathrm{u}}\right)$ vibrational mode has not been observed in the emission spectrum (we may tentatively assign the line at $31868 \mathrm{~cm}^{-1}$ to the $\nu_{6}\left(T_{2 \mathrm{u}}\right)$ vibration associated with $\Gamma_{7}$ line). It was observed in Ref. [4], but in our opinion it should be reassigned because the line 3 in the emission spectrum at $31896 \mathrm{~cm}^{-1}$ is at $55 \mathrm{~cm}^{-1}$ from the $\Gamma_{7}$ not at $82 \mathrm{~cm}^{-1}$ (see Table IV in Ref. [4]).

At $140 \mathrm{~cm}^{-1}$ from the upper energy site of the ${ }^{6} P_{7 / 2}$ term there is a group of four peaks. We assigned these lines to an emission of $\mathrm{Gd}^{3+}$ ions in another crystallographic site. Four components of the ${ }^{6} P_{7 / 2} \rightarrow{ }^{8} S_{7 / 2}$ transition are observed, it points to a lower symmetry of the emitting ions.

\section{Conclusions}

In the present paper we have presented vibronic spectra of $\mathrm{Gd}^{3+}$ in the $\mathrm{Cs}_{2} \mathrm{NaGdCl}_{6}$ elpasolite crystal followed by one- and two-photon processes. We have found that the phonon symmetries of vibronic transitions are odd parity at either kind of spectroscopy. However, their structure is different. This result is in 
opposite to the two-photon absorption spectra reported by McClure et al. [2] for octahedral crystals doped with transition metals, which have observed even parity modes. This difference is most probably due to a different mechanism of two-photon vibronic transitions occurring in $\mathrm{Gd}^{3+}$ ions [6]. The nature of two-photon vibronic transitions is under investigation.

\section{References}

[1] See for example T.R. Faulkner, F.S. Richardson, Mol. Phys. 35, 1141 (1978).

[2] S.A. Payne, A.B. Goldberg, D.S. McClure, J. Chem. Phys. 78, 3688 (1983).

[3] A.J. de Vries, G. Blasse, J. Chem. Phys. 88, 7312 (1988).

[4] M. Bouazaoui, B. Jacquier, C. Linares, W. Stręk, J. Phys., Condens. Matter 3, 921 (1991).

[5] J. Sztucki, W. Stręk, Phys. Rev B 34, 3120 (1986).

[6] J. Sztucki, J. Phys., Condens. Malter 5, 6773 (1993).

[7] A. Lentz, J. Phys. Chem. Solids 35, 827 (1974).

[8] C. de Mello Donegá, A. Meijerink, J. Lumin. 55, 315 (1993). 